Jarden Rebecca (Orcid ID: 0000-0003-4643-7147)

\title{
Strengthening workplace wellbeing: Perceptions of intensive care nurses
}

1) Rebecca Jarden (first \& corresponding author): M.N., R.N.; Department of Nursing, Melbourne School of Health Sciences, 161 Barry St, Carlton, Victoria 3053, Australia \& School of Clinical Sciences, Auckland University of Technology (AUT), North Shore Campus, 90 Akoranga Drive, Northcote, Auckland 0627, New Zealand; phone: 00614 77444548; rebecca.jarden@unimelb.edu.au.

2) Margaret Sandham: (research team member); BHSc (Nursing), DClinPsych., School of Clinical Sciences, Auckland University of Technology (AUT), North Shore Campus, 90 Akoranga Drive, Northcote, Auckland 0627, New Zealand; margaret.sandham@aut.ac.nz.

3) Richard Siegert: (research team member); Ph.D.; School of Clinical Sciences and School of Public Health and Psychosocial Studies, Auckland University of Technology (AUT), North Shore Campus, 90 Akoranga Drive, Northcote, Auckland 0627, New Zealand; richard.siegert@aut.ac.nz.

4) Jane Koziol-McLain: (research team member); Ph.D., R.N.; School of Clinical Sciences, Auckland University of Technology (AUT), North Shore Campus, 90 Akoranga Drive, Northcote, Auckland 0627, New Zealand; jane.koziol-mclain@aut.ac.nz.

\section{Abstract}

Background: Intensive care nursing is a professionally challenging role, elucidated in the body of research focusing on nurses' illbeing, including burnout, stress, moral distress, and compassion fatigue. Although scant, research is growing in relation to the elements contributing to critical care nurses' workplace wellbeing. Little is currently known about how intensive care nurse wellbeing is strengthened in the workplace, particularly from the intensive care nurse perspective.

Aims and objectives: Identify intensive care nurses' perspectives of strategies that strengthen their workplace wellbeing.

Design: An inductive descriptive qualitative approach was used to explore intensive care nurses' perspectives of strengthening work wellbeing.

Method: New Zealand intensive care nurses were asked to report strategies strengthening their workplace wellbeing in two free text response items within a larger online survey of wellbeing. Findings: Sixty-five intensive care nurses identified 69 unique strengtheners of workplace wellbeing. Strengtheners included nurses drawing from personal resources, such as mindfulness, and yoga. Both relational and organisational systems strengtheners were also evident, including peer supervision, formal debriefing, and working as a team to support each other.

Conclusions: Strengtheners of intensive care nurses' workplace wellbeing extended across individual, relational and organisational resources. Actions such as simplifying their lives, giving and receiving team support, and accessing employee assistance programmes were just a few of the intensive care nurses' identified strengtheners. These findings inform future strategic workplace wellbeing programmes, creating opportunities for positive change.

Relevance to clinical practice: Intensive care nurses have a highly developed understanding of workplace wellbeing strengtheners. These strengtheners extend from the personal to inter-

This is the author manuscript accepted for publication and has undergone full peer review but has not been through the copyediting, typesetting, pagination and proofreading process, which may lead to differences between this version and the Version of Record. Please cite this article as doi: $10.1111 /$ nicc.12386 
professional to organisational. The extensive range of strengtheners the nurses have identified provide a rich source for the development of future workplace wellbeing programmes for critical care.

Key words: workplace wellbeing, ICU nursing, critical care nursing, positive psychology intervention.

\section{Background}

Research about intensive care unit (ICU) nurses has largely focused on illbeing (or the 'negative side' of wellbeing) and recovery from illbeing rather than on preventing illbeing or promoting wellbeing (Jarden et al., Under review-b, Jarden et al., Under review-a). The research base is strongly skewed towards nurses' experiences of burnout (Zarei et al., 2016, Vévoda et al., 2016, Pereira et al., 2016, Weigl et al., 2016), compassion fatigue (Sacco et al., 2015), moral distress (De Villers and DeVon, 2013, Choe et al., 2015, O'Connell, 2014), and stress (Borteyrou et al., 2014, Dewe, 1987, Burgess et al., 2010). Until 2018, primary research of ICU nurse wellbeing was limited to four studies on spiritual wellbeing (Azarsa et al., 2015), team commitment (Galletta et al., 2016), effects of a mindfulness programme (Hee Kim et al., 2014), and emotional wellbeing (Siffleet et al., 2015). These four studies lacked a common definition of wellbeing and had limited generalisability (Jarden et al., Under review-b). More recently, ICU nurse conceptions of workplace wellbeing were explored in a prototype analysis, which is a study that investigates the key features of a concept (Jarden et al., In-press). Workload and work-life balance were identified as central characteristics of their wellbeing, alongside feeling valued, and experiencing respect and having workplace support. The current study extends the knowledge base of ICU nurse workplace wellbeing, exploring strengthbuilding opportunities as identified by ICU nurses.

Identifying strength-building opportunities aligns with the developing area of research called positive organisational scholarship (Cameron et al., 2003b). Positive organisational scholarship (POS) studies what is positive, flourishing, and life-giving in organisations (Cameron et al., 2003b). Drawing from the heliotropic effect in which living systems have a tendency towards positive and life-giving forces, POS seeks out these in the organisational context (Cameron and McNaughtan, 2014). Positive organisational scholarship moves from the problem-focused and deficit-based inquiry towards new ways of understanding positive outcomes in organisations (Cameron et al., 2003b), for example, appreciative inquiry (Cooperrider and McQuaid, 2012). Although negative events strongly overshadow positive events (e.g., see Baumeister et al., 2001), creating positive change is thought to require both (Cameron, 2008). Given the strength of the negative, Cameron (2008) proposes more emphasis on the positive is required for positive change to occur. Whilst adversities and difficulties still occur, the challenges and obstacles are reframed as opportunities and strength-building experiences. Gittell et al. (2006) give the example of "accepting the short-term costs of excess staffing levels to maintain positive human relationships in the face of adversity" (p. 324), as opposed to redundancies and cost-savings in response to a financial crisis.

Work wellbeing interventions in nursing are largely focused towards recovery from illbeing, rather than preventing illbeing or promoting wellbeing. For example, quiet time to reduce stress levels (Riemer et al., 2015), yoga for stress and anxiety management (Bernstein et al., 2015), and mindfulness for stress management (Pipe et al., 2009). An exception is the investigation by Hee Kim et al. (2014) into the effects of mindfulness training on mindfulness and subjective happiness. Adopting this positive lens allows for exploration and an emphasis on resourcefulness in creating 
positive change (Cameron and McNaughtan, 2014), potentially for ICU nurses.

\section{Context}

The ICU registered nurse provides specialised expertise managing complex and challenging situations with patients, patients' families, and inter-professional teams. In New Zealand, 2,245 registered nurses (4.5\% of the local nursing workforce) identify as working in one of 30 ICUs (Nursing Council of New Zealand, 2015, Australian and New Zealand Intensive Care Society Centre for Outcome and Resource Evaluation, 2015). These nurses are exposed to various psychological risks whilst working with patients experiencing life-threatening situations. These risks include personal or family health concerns or crises, high patient acuity, changes in technology, and working rotating night shifts or extended shift hours. Given such stressors, nurses may be vulnerable to significant psychological harms such as burnout (Epp, 2012, Pereira et al., 2016), compassion fatigue (Jenkins and Warren, 2012), moral distress (Choe et al., 2015) and bullying (Ganz et al., 2015). These stressors provide significant opportunity to draw from psychological capital, and the strengthening evidence base of positive psychology and positive psychological interventions (Hone et al., 2014, Bolier et al., 2013, Sin and Lyubomirsky, 2009, Weiss et al., 2016). Realising this opportunity could draw from the strengths of other initiatives where the "positive" has been added to organisations. Examples include the Brilliance Project (Dadich et al., 2015) which has strong foundations in positive organisational scholarship (Cameron et al., 2003a) and appreciative inquiry (Cooperrider and Whitney, 2005); Magnet hospitals (Laschinger et al., 2001, Scott et al., 1999); using the positive organisational scholarship lens and a foundation of the humanistic work ideology, the Big Hospital study examined an organization driven by humanitarian principles (Wooten and Crane, 2004). Examples of further "positive" interventions include the Reflected Best-Self Instrument (Spreitzer et al., 2009), Appreciative Inquiry Summits (Cooperrider and Whitney, 2005); Job Crafting (Berg et al., 2010), and Everest goals (Cameron and Plews, 2012).

Applied positive psychology provides new opportunities to develop initiatives aligned with key national strategies. For example, the working vision of the New Zealand Ministry of Health (2015) seeks to achieve a health and disability system that focuses on wellbeing and prevention ( $p$. 2). With this aspirational policy in mind, and given the diversity in the ICU nursing workforce, innovative ways of working are necessary to meet the challenges of ICU nursing. Individuals involved in building these new ways of working in organisations have the potential to draw from the positive experiences of others in relation to principles, structures, practices and cultures (Laloux, 2014). Previous research has identified characteristics of ICU nurse workplace wellbeing (Jarden et al., Inpress), this study seeks to identify strategies to foster workplace wellbeing.

\section{Research objectives}

Research questions investigated:

1) What do ICU nurses think may enhance their workplace wellbeing (potential strengtheners)?

2) What strategies do ICU nurses currently use to enhance their workplace wellbeing (actual strengtheners)?

This research will identify New Zealand ICU RN's perspectives of strengtheners of workplace 
wellbeing in their context. These perspectives will inform individuals, teams, organisations and policy makers of the potential strengtheners of workplace wellbeing. As such, the opportunities for improved ICU nurse performance, engagement, retention, and patient satisfaction may be enabled and realised.

\section{Methods}

This qualitative descriptive study (e.g., see Sandelowski, 2000) reports the findings from a dataset of two online free-text open-ended questions. Participants also took part in a prototype analysis (see Jarden et al., In-press). The questionnaire asked participants to list actual and potential strengtheners of their workplace wellbeing in two questions:

\section{Question One: "What do you think would promote/enable/facilitate work wellbeing"}

Question Two: "What strategies, tools, initiatives, and/or programmes are currently used in your workplace to promote/enable/facilitate your work wellbeing. Please list things you do (individual level), things your team does (team level), and things your organisation does (organisation level)."

\section{Participant selection}

Purposeful sampling of registered nurses working in a New Zealand ICU (Nursing Council of New Zealand, 2015) was conducted through national professional bodies (e.g., New Zealand College of Critical Care Nurses and New Zealand Nurses' Organisation), New Zealand ICU research nurses,

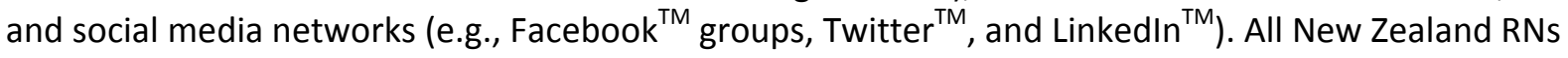
presently employed in an ICU were eligible for selection.

\section{Ethical considerations}

This research was conducted in accordance with Auckland University of Technology Ethics Committee approval (17/180). Advertisements provided potential participants with a URL to the study information webpage. The study information webpage requested participants to indicate their informed consent by entering their name and e-mail address for the study URL to then be emailed to them.

\section{Data analysis}

Using applied thematic analysis (Guest et al., 2012, Braun and Clarke, 2006, Braun and Clarke, 2013), the free-responses in this exploratory study were analysed using a six-phase contentdriven, inductive approach to coding. After reviewing and becoming familiar with the data, initial codes were identified (RJ), drawing from explicit written statements by the participants. Two researchers (RJ \& MS) categorised codes into three levels, consistent with the initial probe questions. The framework of ' $m e$ ', 'we', and 'us' (Jarden and Jarden, 2016) was identified as an adaptable, user-friendly, flexible and highly applicable conceptual scheme to support the identification of levels for the strengtheners of ICU nurse workplace wellbeing. The framework was adapted for this study (with permission from the authors), applying the term 'me' to the personal or individual resources nurses bring to ICU, 'we' to the relational experiences of working in the ICU, and 
'us' to the organisational systems the ICU nurses work within. For rigour in this process, researchers categorised the codes first independently, then compared and contrasted together. A third researcher (JKM) reviewed and resolved any uncertainty in relation to the categorising.

\section{Findings}

Eighty-Two New Zealand ICU nurses opted in to the study. Of these 82 nurses, 65 participated in the study by responding to the online questions. Three of the 65 provided incomplete data, their partial data were used in the analysis. Participants $(n=65)$ were primarily married $(n=$ 40; 62\%) women ( $n=57 ; 88 \%$ ), aged between 25 and 63 years, and identified as New Zealand European $(n=45 ; 69 \%)$. This was a largely representative sample of the New Zealand ICU nurse population.

Firstly, monolexemic linguistic items (i.e., meaningful individual words) were identified, for example, "support", "supervision", and "respect". Items with modifiers were coded as single items, for example, "more support" was coded as "support". Where a phrase was used, a coding decision was made. For example, "feeling supported when things don't go as planned", was coded as "support". A conservative approach to the coding preserved the integrity and richness of the data. For example, "regular feedback" was left as two items rather than coding to a single item, e.g., "feedback". A total of 153 words and phrases were reported for potential strengtheners of workplace wellbeing, and 213 for actual strengtheners of workplace wellbeing. Of these words and phrases, 69 unique linguistic items were identified (see strengtheners in Appendix A).

Secondly, codes were categorised, 22 were applied to the 'me' level, 14 to 'we', and 33 to 'us'. The participants' explicit words were retrieved from the data to provide a richer description of each of the three categories in relation to either the actual or potential strengtheners of ICU nurse workplace wellbeing.

\section{Me (personal or individual resources nurses bring to ICU)}

For potential strengtheners, participants suggested they would like the "ability to take sick leave without feeling guilty", and they would like to see an "ongoing attitudinal change that taking care of yourself - the clinician - is a priority before you are able to care for others". Other participants suggested they'd like to see better work-life balance and have the ability to reflect on stressful events "in a positive manner for learning".

For actual strengtheners, participants highlighted the importance of work-life balance, for example, "I set boundaries for how many shifts I do each week, i.e., depending on how tired I feel as to whether I do extras". Others stated the benefits of engaging in activities outside of work time, for example, "sports outside work (swimming, snowboarding), leaving work behind completely after hrs or during my days off and I do not do on call". Spirituality was also identified as an actual strengthener, for example, "prayer for the workplace - both for my colleagues and patients". Reducing work hours was mentioned in a variety of ways, for example, "I work part time to suit the tiredness associated with shift work and aging".

\section{We (relational experiences of working in the ICU)}

For potential strengtheners, one participant captured the complexity of the relational experiences by suggesting 
I'm not a hundy [hundred] percent on if there is one main solution - I'm not sure, but I think it might take a long time of continuous positive interventions and collaboration between all of the team...giving time to listen to one another, feeling confident in our work and our teammates (continued education and opportunities to develop), safe staffing levels, maybe having a 'diffuse room' where you could go to take some time out....

Another participant felt the key could be

a supportive team environment. To me, the most important aspect of this is team. If I show up to work knowing that I'm not going to have to struggle to find someone to help me mobilise my patient or bounce ideas off of then I know that I will work hard but not leave a shift feeling like I did my best for the patient. Being isolated in a nursing role is a recipe for disaster not only for the patient but for the wellbeing of the nurse

and another suggested

regular encouragement and appreciation I find boosts confidence and morale in all staff, not just new staff. Respecting those we work with and taking time to listen and make people feel wanted and part of the team. Extra resources do help but I think if we are working with good people then even the busiest days are good

For actual strengtheners, participants stated a "mindfulness week, some peer supervision (not often enough yet), and formal debriefing when required". Others focused on working as a team to support each other and communicate effectively, for example, "the team ensure breaks are taken at appropriate times. Good support is given during crisis situations - work and home...regular team meetings occur when anyone can raise issues".

\section{Us (the organisational systems nurses work within)}

For potential strengtheners, participants suggested activities to promote their work-life balance, such as "not being hassled via texts to work extra shifts", and "rosters to acknowledge some people do not do nights well and some do not do day shifts well". Clinical supervision was also identified, as one participant stated

allied health must have clinical supervision to retain their practicing certificate yet we at the front-line have no resource for clinical supervision. We see a lot with no resource for debriefing or clinical supervision. More formal debriefing would allow a better understanding of medical decision making and allow a more multi-disciplinary approach to patient care. It also means staff do not end up taking things home with them or feeling perhaps they could have done better

The perceptions of "good staffing" was perceived as a potential strengthener, such as " $100 \%$ staffing at all times". However, another participant suggested that in times of "good staffing", protection from redeployment was seen as important, for example, "not being redeployed the moment there is a second of downtime especially when all study leave is cancelled for 6 months of the year during the 'busy' period". Others highlighted the importance of "better pay - feeling valued in a monetary 
sense" and "adequate training and individualised plans for professional growth (that are followed through)".

For actual strengtheners, participants identified both internal and external psychological support structures such as both formal and informal debriefing, trained counsellors and a psychologist, and employee assistance programmes. Other participants stated their organisations arranged group activities such as "pilates, yoga, boot-camp and spinning classes" alongside subsidised gym memberships and meditation classes. One participant identified a strengthener was their roster which "takes into account preferences and requests, and also sticks to the MECA [MultiEmployer Collective Agreement]".

\section{Intensive care nurse multi-level workplace wellbeing intervention programme}

The socio-ecological framework (Bronfenbrenner, 1977b) is purported to inspire multi-level interventions, yet frequently public health interventions have single-level targets and are focused on intrapersonal change (Schölmerich and Kawachi, 2016). Drawing from the ecological framework (Bronfenbrenner, 1977a), the eco-social approach (Krieger, 1994), the health promotion adaption of the socio-ecological framework (McLeroy et al., 1988), and the "Me, We, Us" framework (Jarden and Jarden, 2016), an example of what a multi-level workplace wellbeing intervention programme might look like is depicted in Figure 1. This figure integrates examples of the ICU nurses' strengtheners, potential interventions from the literature (Roberts et al., 2005, Wrzesniewski and Dutton, 2001, Page and Vella-Brodrick, 2013) and the "Me, We, Us" framework.

\section{Discussion}

The ICU nurses identified strengtheners at the individual, team and organisational levels. These findings are misaligned with many organisational initiatives to enhance workplace wellbeing which are largely focussed towards strengthening an individual's personal resources (Day and Penney, 2017). In fact, this large list of individual strengtheners would suggest that ICU nurses have a highly developed understanding of personal workplace wellbeing strengtheners. The words "less" and "reduce" were evident throughout the data in relation to key terms such as "overtime" and "oncall" and "nights" and "extras". These words are consistent with the concept of simplicity and simplifying your life, which is an area gaining more attention in the literature in relation to personal wellbeing (Rich et al., 2017a, Rich et al., 2017b). Most of the personal workplace wellbeing strengtheners were also actual, rather than potential, strengtheners. Thus, most are strengtheners currently being used by the ICU nurses. In contrast, the organisational strengtheners were predominantly reported as potential strengtheners of wellbeing, meaning they are not being currently used. This suggests an opportunity to capitalise on these potential strengtheners identified by the ICU nurses, such as "courses to promote wellbeing", "appreciation", and "fair pay".

Job and workplace design are proposed in the literature as key areas where workplace wellbeing may be enhanced (Munir and McDermott, 2013). Firstly, at a primary-organisational intervention level, strategies include job redesign (see Carlgren et al., 2014, Nielsen and Christensen, 2014, Sangiorgi and Junginger, 2015, Roberts et al., 2016), job crafting (Kulik et al., 1987, Berg et al., 2010, van den Heuvel et al., 2015, Ghitulescu, 2015, Bipp and Demerouti, 2015, Tims et al., 2015) and structural changes to organisational processes and policies (see Guenole and Biggs, 2013). Examples of strengtheners identified by the ICU nurses in relation to this primary-organisational intervention levelincluded preventative workplace wellbeing programmes to promote wellbeing and supporting 
safe staffing levels. Secondly, at a secondary individual intervention level strategies include stress management, CBT or mindfulness education (see Houdmont et al., 2013, Tan et al., 2014, Hyland et al., 2015, Malik et al., 2014, Furlan et al., 2012, Rongen et al., 2013, Geaney et al., 2013). Examples of strengtheners identified by the ICU nurses at this secondary individual intervention level included mindfulness and yoga. Mindfulness as a strengthener resonates with previous literature such as (Hee Kim et al., 2014). Thirdly, at a tertiary individual intervention level strategies include counselling, employee assistance programmes, rehabilitation and organisationally supported wellness programmes to support those with identified problems (e.g., Robbins and Judge, 2013, Colquitt et al., 2013). Examples of strengtheners identified by the ICU nurses at this tertiary individual intervention level included "counsellors" and "employee assistance programmes". Alternative ICU nurse identified strengtheners such as "pilates, yoga, boot-camp and spinning classes", "courses to promote wellbeing", subsidised gym memberships and meditation classes are opportunities yet to be empirically tested in the ICU nurse workplace.

There is strong evidence to support the important place of negative events in generating positive outcomes (e.g., see Baumeister et al., 2001). However, positive practices such as compassionate support for employees and expressions of gratitude predict organisational performance (Cameron et al., 2011). Since positive psychology began in 1998 (Seligman and Csikszentmihalyi, 2000), key research areas that have developed in relation to workplace wellbeing include Positive Organisational Behaviour (Luthans, 2002a), Positive Organisational Scholarship (Cameron et al., 2003a), and Positive Organisational Change (Cameron and McNaughtan, 2014). Within these research areas is a focus towards strengths and psychological capacities (Luthans, 2002b), examining the best of the human condition (Cameron et al., 2003a, Spreitzer and Sonenshein, 2003), and tapping into collective intelligence (or the knowledge gained through collaboration; Lewis, 2016). The potential strengtheners reported by the ICU nurses demonstrates the benefits of seeking out the collective intelligence. This study has drawn from the strengths and psychological capabilities of the ICU nurses, and now, disseminating this intelligence supports the cocreation of change in relation to ICU nurse wellbeing.

\section{Strengths and Limitations}

This dataset was obtained during the online collection of data for a prototype analysis exploring ICU nurse conceptions of workplace wellbeing. Strengths of the study include the strong contribution of the ICU nurses who shared their knowledge and experiences to support this exploration. Use of the participants' quotes throughout the findings demonstrates the authors' appreciation of the value of their voice. Support of the professional nursing organisations of New Zealand, alongside the social media networks to recruit participants was invaluable, and enabled a 'bottom-up' approach in the recruitment processes, preventing potential workplace and organisational barriers influencing participation. Given the findings are based on a single New Zealand sample, generalisability to other nations is limited. Greater depth and insight into the strengtheners of workplace wellbeing may have been obtained had we used a triangulated approach to data collection by incorporating both focus groups and interview data, however these additional data collection methods were outside the scope of this research and provide strong foundations for future research opportunities. 


\section{Implications for practice}

Unique strengtheners of workplace wellbeing were identified by the New Zealand intensive care nurses. Actions such as simplifying lives, mindfulness, yoga, peer supervision, and working as a team to support each were just a few of the intensive care nurses' identified strengtheners. This collective intelligence provides a robust foundation to inspire future multi-level workplace wellbeing programmes.

\section{Conclusions}

This study has identified that New Zealand ICU nurses have a robust complement of personal resources they draw from to strengthen their workplace wellbeing, including actions to simplify their lives. Nurses are also cognisant of a wide range of both relational and organisational systems strengtheners, including peer supervision, formal debriefing, and working as a team to support each other. These actions may be incorporated in strategic and theoretically informed workplace wellbeing programmes, drawing from these ICU nurses' collective intelligence to co-create change.

\section{Impacts}

What is known about the subject:

- The research base is strongly skewed towards nurses' experiences of burnout, compassion fatigue, moral distress, and stress.

- Adopting a positive lens allows for exploration and an emphasis on resourcefulness in creating positive change.

- The various psychological risks intensive care nurses face in their workplace provide significant opportunity to draw from psychological capital.

\section{What this paper contributes:}

- A rich foundation of workplace wellbeing strengtheners was identified by New Zealand intensive care nurses.

- Personal, inter-professional, and organisational systems level opportunities to strengthen workplace wellbeing are explored in relation to the literature.

- An example of a multi-level workplace wellbeing intervention programme which demonstrates how the intensive care nurses' collective intelligence may inspire the cocreation of positive change.

\section{Acknowledgements}

Firstly, thank you to the ICU RNs who participated in the study, secondly, thank you to the professional organisations (e.g., NZNO's NZCCCN) that supported study advertising.

Conflict of interest statement: The authors have no conflicts of interest to declare

Funding and financial disclosure: This research has not received funding. 


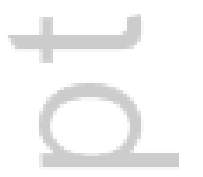

This article is protected by copyright. All rights reserved. 


\section{References}

Australian and New Zealand Intensive Care Society Centre for Outcome and Resource Evaluation (2015). Australian and New Zealand Intensive Care Society Centre for Outcome and Resource Evaluation Annual Report 2013/14, ANZICS CORE, www.anzics.com.au/Pages/CORE/About-CORE.aspx Accessed 18 February 2016.

Azarsa T, Davoodi A, Markani A, Gahramanian A \& Vargaeei A (2015). Spiritual wellbeing: Attitude toward spiritual care and its relationship with spiritual care competence among critical care nurses. Journal of Caring Science; 4: 309-320.

Baumeister R, Bratslavsky E, Finkenauer C \& Vohs K (2001). Bad is stronger than good. Review of General Psychology; 5: 323-370.

Berg J, Wrzesniewski A \& Dutton J (2010). Perceiving and responding to challenges in job crafting at different ranks: When proactivity requires adaptivity. Journal of Organizational Behavior; 31: 158-186.

Bernstein A, Kobs A, Bar J, Fay S, Doyle J, Golubic M \& Roizen M (2015). Yoga for stress management among intensive care unit staff: A pilot study. Alternative \& Complementary Therapies; 21: 111-115.

Bipp T \& Demerouti E (2015). Which employees craft their jobs and how? Basic dimensions of personality and employees' job crafting behaviour. Journal of Occupational and Organizational Psychology; 88: 631-655.

Bolier L, Haverman M, Westerhof GJ, Riper H, Smit F \& Bohlmeijer E (2013). Positive psychology interventions: A meta-analysis of randomized controlled studies. BMC Public Health; 13: 120.

Borteyrou X, Truchot D \& Rascle N (2014). Development and validation of the Work Stressor Inventory for nurses in oncology: Preliminary findings. Journal of Advanced Nursing; 70: 443453.

Braun V \& Clarke V (2006). Using thematic analysis in psychology. Qualitative Research $n$ Psychology; 3: 77-101.

Braun V \& Clarke V (2013). Successful qualitative research: A practical guide for beginners. London: Sage.

Bronfenbrenner U (1977a). Lewinian space and ecological substance. Journal of Social Issues; 33: 199-212.

Bronfenbrenner U (1977b). Toward an experimental ecology of human development. American psychologist; 32: 513.

Burgess L, Irvine F \& Wallymahmed A (2010). Personality, stress and coping in intensive care nurses: A descriptive exploratory study. Nursing in Critical Care; 15: 129-140.

Cameron K (2008). Paradox in positive organizational change. The Journal of Applied Behavioral Science; 44: 7-24.

Cameron K, Dutton J \& Quinn R (2003a). Organizational virtuousness and performance. In: Cameron K, Dutton J \& Quinn R (eds.) Positive organizational scholarship. San Francisco, CA: BerrettKoehler.

Cameron K, Dutton J \& Quinn R (2003b). Positive organizational scholarship: Foundations of a new discipline. San Francisco, CA: Berrett-Koehler.

Cameron K \& McNaughtan J (2014). Positive organizational change. The Journal of Applied Behavioral Science; 50: 445-462. 
Cameron K, Mora C, Leutscher T \& Calarco M (2011). Effects of positive practices on organizational effectiveness. The Journal of Applied Behavioral Science; 47: 266-308.

Cameron K \& Plews E (2012). Positive leadership in action: Applications of POS by Jim Mallozzi, CEO, Prudential Real Estate and Relocation. Organizational Dynamics; 41: 99-105.

Carlgren L, Elmquist M \& Rauth I (2014). Design thinking: Exploring values and effects from an innovation capability perspective. The Design Journal; 17: 403-423.

Choe K, Kang Y \& Park Y (2015). Moral distress in critical care nurses: A phenomenological study. Journal of Advanced Nursing; 71: 1684-1693.

Colquitt J, Lepine J \& Wesson M (2013). Organizational behaviour: Improving performance and commitment in the workplace. New York: McGraw-Hill/Irwin.

Cooperrider D \& McQuaid M (2012). The positive arc of systemic strengths: How appreciative inquiry and sustainable designing can bring out the best in human systems. The Journal of Corporate Citizenship; 2012: 71-102.

Cooperrider D \& Whitney D (2005). Appreciative inquiry: A positive revolution in change. San Francisco: Berrett-Koehler.

Dadich A, Fulop L, Ditton M, Campbell S, Curry J, Eljiz K, Fitzgerald A, Hayes K, Herington C, Isouard G, Karimi L \& Smyth A (2015). Finding brilliance using positive organizational scholarship in healthcare. Journal of Health Organization and Management; 29: 750-777.

Day A \& Penney S (2017). Essential elements of organizational initiatives to improve workplace wellbeing. In: Cooper C \& Leiter M (eds.) The Routledge Companion to Wellbeing at Work. New York: Routledge.

De Villers M \& DeVon H (2013). Moral distress and avoidance behavior in nurses working in critical care and noncritical care units. Nursing Ethics; 20: 589-603.

Dewe P (1987). Identifying the causes of nurses' stress: A survey of New Zealand nurses. Work \& Stress; 1: 15-24.

Epp K (2012). Burnout in critical care nurses: A literature review. Dynamics: The Official Journal of the Canadian Association of Nurses; 23: 25-31.

Furlan A, Gnam W, Carnide N, Irvin E, Amick B, DeRango K, McMaster R, Cullen K, Slack T, Brouwer S \& Bültmann U (2012). Systematic Review of Intervention Practices for Depression in the Workplace. Journal of Occupational Rehabilitation; 22: 312-321.

Galletta M, Portoghese I, Coppola R, Finco G \& Campagna M (2016). Nurses well-being in intensive care units: Study of factors promoting team commitment. Nursing in Critical Care; 21: 146156.

Ganz F, Levy H, Khalaila R, Arad D, Bennaroch K, Kolpak O, Drori Y, Benbinishty J \& Raanan O (2015). Bullying and its prevention among intensive care nurses. Journal of Nursing Scholarship; 47: 505-511.

Geaney F, Kelly C, Greiner BA, Harrington JM, Perry IJ \& Beirne P (2013). The effectiveness of workplace dietary modification interventions: A systematic review. Preventive Medicine; 57: 438-447.

Ghitulescu B (2015). Job crafting. Volume 5. Wiley Encyclopedia of Management.

Gittell J, Cameron K, Lim S \& Rivas V (2006). Relationships, layoffs, and organizational resilience: Airline industry responses to September 11. The Journal of Applied Behavioral Science; 42: 300-329.

Guenole N \& Biggs D (2013). Organisational development and change. In: Lewis R \& Zibarras L (eds.) Work and occupational psychology: Integrating theory and practice. London: Sage. 
Guest G, MacQueen K \& Namey E (2012). Applied thematic analysis. Thousand Oaks, California: SAGE Publications, Inc.

Hee Kim L, Subramanian P, Rahmat N \& Phang Cheng K (2014). The effects of mindfulness training program on reducing stress and promoting well-being among nurses in critical care units. Australian Journal of Advanced Nursing; 31: 22-31.

Hone L, Jarden A \& Schofield G (2014). An evaluation of positive psychology intervention effectiveness trials using the RE-AIM framework: A practice-friendly review. The Journal of Positive Psychology; 10: 303-322.

Houdmont J, Randall R, Kerr R \& Addley K (2013). Psychosocial risk assessment in organizations: Concurrent validity of the brief version of the Management Standards Indicator Tool. Work \& Stress; 27: 403-412.

Hyland P, Lee R \& Mills M (2015). Mindfulness at work: A new approach to improving individual and organizational performance. Industrial \& Organizational Psychology; 8: 576-602.

Jarden A \& Jarden R (2016). Positive psychological assessment for the workplace. In: Oades L, Steger M, Della-Fave A \& Passmore J (eds.) The Wiley Blackwell Handbook of the psychology of positivity and strengths-based approaches at work. New York, NY: Wiley.

Jarden R, Narayanan A, Sandham M, Siegert R \& Koziol-McLain J (Under review-a). Mapping ICU nurse wellbeing: Development and application of the iAnalysis model. TBC Journal of Professional Nursing.

Jarden R, Sandham M, Siegert R \& Koziol-McLain J (In-press). Intensive care nurse conceptions of wellbeing: A prototype analysis. TBC Nursing in Critical Care.

Jarden R, Sandham M, Siegert R \& Koziol-McLain J (Under review-b). Intensive care nurse wellbeing: A systematic review. TBC Australian Critical Care.

Jenkins B \& Warren N (2012). Concept analysis: Compassion fatigue and effects upon critical care nurses. Critical Care Nursing Quarterly; 35: 388-395.

Krieger N (1994). Epidemiology and the web of causation: Has anyone seen the spider? Social science \& medicine; 39: 887-903.

Kulik C, Oldham G \& Hackman J (1987). Work design as an approach to person-environment fit. Journal of Vocational Behavior; 31: 278-296.

Laloux F (2014). Reinventing organizations: A guide to creating organizations inspired by the next stage of human consciousness. Brussels: Nelson Praker.

Laschinger H, Shamian J \& Thomson D (2001). Impact of magnet hospital characteristics on nurses' perceptions of trust, burnout, quality of care, and work satisfaction. Nursing Economics; 19: 209-219.

Lewis S (2016). Positive psychology and change: How leadership, collaboration and appreciative inquiry create transformational results. Hoboken: Wiley.

Luthans $F$ (2002a). The need for and meaning of positive organizational behavior. Journal of Organizational Behavior; 23: 695-706.

Luthans F (2002b). Positive organizational behavior: Developing and managing psychological strengths. Academy of Management Executive; 16: 57-72.

Malik S, Blake H \& Suggs L (2014). A systematic review of workplace health promotion interventions for increasing physical activity. British Journal of Health Psychology; 19: 149-180.

McLeroy K, Bibeau D, Steckler A \& Glanz K (1988). An ecological perspective on health promotion programs. Health Education \& Behavior; 15: 351-377.

Ministry of Health (2015). Updating the New Zealand health strategy: Progress to date. Wellington, 
NZ: Ministry of Health.

Munir F \& McDermott H (2013). Design of environments and work: Health, safety and well-being. In: Lewis R \& Zibarras L (eds.) Work and occupational psychology: Integrating theory and practice. London: Sage.

Nielsen SL \& Christensen PR (2014). The Wicked Problem of Design Management: Perspectives from the Field of Entrepreneurship. The Design Journal; 17: 560-582.

Nursing Council of New Zealand (2015). The New Zealand nursing workforce: A profile of nurse practitioners, registered nurses and enrolled nurses. Wellington, NZ: NCNZ.

O'Connell C (2014). Gender and the experience of moral distress in critical care nurses. Nursing Ethics.

Page K \& Vella-Brodrick D (2013). The working for wellness program: RCT of an employee well-being intervention. Journal of Happiness Studies; 14: 1007-1031.

Pereira S, Teixeira C, Carvalho A \& Hernández-Marrero P (2016). Compared to palliative care, working in intensive care more than doubles the chances of burnout: Results from a nationwide comparative study. PLoS One; 11.

Pipe TB, Bortz JJ, Dueck A, Pendergast D, Buchda V \& Summers J (2009). Nurse leader mindfulness meditation program for stress management: a randomized controlled trial. J Nurs Adm; 39.

Rich S, Hanna S \& Wright B (2017a). Simply satisfied: The role of psychological need satisfaction in the life satisfaction of voluntary simplifiers. Journal of Happiness Studies; 18: 89-105.

Rich S, Hanna S, Wright B \& Bennett P (2017b). Fact or fable: Increased wellbeing in voluntary simplicity. International Journal of Wellbeing; 7.

Riemer H, Mates J, Ryan L \& Schleder B (2015). Decreased stress levels in nurses: A benefit of quiet time. American Journal of Critical Care; 24: 396-402.

Robbins S \& Judge T (2013). Organizational behaviour. New Jersey: Prentice Hall.

Roberts J, Fisher T, Trowbridge M \& Bent C (2016). A design thinking framework for healthcare management and innovation. Healthcare; inpress.

Roberts L, Dutton J, Spreitzer G, Heaphy E \& Quinn R (2005). Composing the reflected best-self portrait: Building pathways for becoming extraordinary in work organizations. Academy of Management Review; 30: 712-736.

Rongen A, Robroek S, van Lenthe F \& Burdorf A (2013). Workplace health promotion: A metaanalysis of effectiveness. American Journal of Preventive Medicine; 44: 406-415.

Sacco T, Ciurzynski S, Harvey M \& Ingersoll G (2015). Compassion satisfaction and compassion fatigue among critical care nurses. Critical Care Nurse; 35: 32-44.

Sandelowski M (2000). Whatever happened to qualitative description? Research in Nursing \& Health; 23: 334-340.

Sangiorgi D \& Junginger S (2015). Emerging issues in service design. The Design Journal; 18: 165-170.

Schölmerich V \& Kawachi I (2016). Translating the socio-ecological perspective into multilevel interventions: Gaps between theory and practice. Health Education \& Behavior; 43: 17-20.

Scott J, Sochalski J \& Aiken L (1999). Review of magnet hospital research: Findings and implications for professional nursing practice. Journal of Nursing Administration; 29: 9-19.

Seligman M \& Csikszentmihalyi M (2000). Positive psychology. An introduction. American Psychologist; 55: 5-14.

Siffleet J, Williams A, Rapley P \& Slatyer S (2015). Delivering best care and maintaining emotional wellbeing in the intensive care unit: The perspective of experienced nurses. Applied Nursing Research; 28: 305-310. 
Sin NL \& Lyubomirsky S (2009). Enhancing well-being and alleviating depressive symptoms with positive psychology interventions: A practice-friendly meta-analysis. Journal of Clinical Psychology; 65: 467-487.

Spreitzer G \& Sonenshein S (2003). Positive deviance and extraordinary organizing. In: Cameron K, Dutton J \& Quinn R (eds.) Positive organizational scholarship. San Francisco: Berrett-Kohler.

Spreitzer G, Stephens J \& Sweetman D (2009). The Reflected Best Self field experiment with adolescent leaders: exploring the psychological resources associated with feedback source and valence. The Journal of Positive Psychology; 4: 331-348.

Tan L, Wang M, Modini M, Joyce S, Mykletun A, Christensen H \& Harvey S (2014). Preventing the development of depression at work: A systematic review and meta-analysis of universal interventions in the workplace. BMC Medicine; 12: 1-11.

Tims M, Bakker A \& Derks D (2015). Examining job crafting from an interpersonal perspective: Is employee job crafting related to the well-being of colleagues? Applied Psychology; 64: 727753.

van den Heuvel M, Demerouti E \& Peeters MCW (2015). The job crafting intervention: Effects on job resources, self-efficacy, and affective well-being. Journal of Occupational and Organizational Psychology; 88: 511-532.

Vévoda J, Vévodová Š, Nakládalová M, Grygová B, Kisvetrová H, Grochowska Niedworok E, Chrastina J, Svobodová D, Przecsková P \& Merz L (2016). The relationship between psychological safety and burnout among nurses. Pracovni Lekarstvi; 68: 40-46.

Weigl M, Stab N, Herms I, Angerer P, Hacker W \& Glaser J (2016). The associations of supervisor support and work overload with burnout and depression: A cross-sectional study in two nursing settings. Journal of Advanced Nursing; 72: 1774-1788.

Weiss L, Westerhof G \& Bohlmeijer E (2016). Can we increase psychological well-being? The effects of interventions on psychological well-being: A meta-analysis of randomized controlled trials. PLOS ONE; 11: e0158092.

Wooten L \& Crane P (2004). Generating dynamic capabilities through a humanistic work ideology: The case of a certified-nurse midwife practice in a professional bureaucracy. American Behavioral Scientist; 47: 848-866.

Wrzesniewski A \& Dutton J (2001). Crafting a job: Revisioning employees as active crafters of their work. The Academy of Management Review; 26: 179-201.

Zarei E, Khakzad N, Reniers G \& Akbari R (2016). On the relationship between safety climate and occupational burnout in healthcare organizations. Safety Science; 89: 1-10. 
Page, K., \& Vella-Brodrick, D. (2013). The working for wellness program: RCT of an employee well-being intervention. Journal of Happiness Studies, 14(3), 1007-1031. doi:10.1007/s10902-012-9366-y

Roberts, L., Dutton, J., Spreitzer, G., Heaphy, E., \& Quinn, R. (2005). Composing the reflected best-self portrait: Building pathways for becoming extraordinary in work organizations. Academy of Management Review, 30(4), 712-736. doi:10.5465/AMR.2005.18378874

Wrzesniewski, A., \& Dutton, J. (2001). Crafting a job: Revisioning employees as active crafters of their work. The Academy of Management Review, 26(2), 179-201. doi:10.2307/259118 


\section{University Library}

\section{- M M I N E R VA A gateway to Melbourne's research publications}

Minerva Access is the Institutional Repository of The University of Melbourne

Author/s:

Jarden, RJ;Sandham, M;Siegert, RJ;Koziol-McLain, J

Title:

Strengthening workplace well-being: perceptions of intensive care nurses

Date:

2019-01-01

Citation:

Jarden, R. J., Sandham, M., Siegert, R. J. \& Koziol-McLain, J. (2019). Strengthening workplace well-being: perceptions of intensive care nurses. NURSING IN CRITICAL CARE, 24 (1), pp.15-23. https://doi.org/10.1111/nicc.12386.

Persistent Link:

http://hdl.handle.net/11343/284481 